\title{
Early and midterm outcomes of triple patch technique for postinfarction ventricular septal defects
}

\author{
Yuki Okamoto, MD, Kazuo Yamamoto, MD, Fuyuki Asami, MD, Mitsuhiro Kimura, MD, \\ Masahiro Mizumoto, MD, Yuka Okubo, MD, and Shinpei Yoshii, MD
}

\begin{abstract}
Objective: Early and midterm outcomes were evaluated in patients who had postinfarction ventricular septal defect (VSD) and underwent VSD repair using the triple patch technique.

Methods: Twenty-one patients underwent VSD repair for postinfarction VSD between April 2004 and September 2015. A retrospective analysis of all in-hospital and postdischarge data was performed. In addition, we compared pre- and perioperative variables between survivors and nonsurvivors.
\end{abstract}

Results: Thirty-day mortality was $23.8 \%$ (5 patients). Three patients died due to low output syndrome and 2 patients died due to sepsis. All of these patients were in cardiogenic shock preoperatively. Although 3 patients had a small residual shunt after surgery, the residual shunt disappeared 6 months after surgery in 1 patient and has been decreasing gradually in another. The mean follow-up was $43.5 \pm 36.1$ months. Overall survival rates (Kaplan-Meier method) at 3 and 8 years were $70.8 \%$ and $57.9 \%$, respectively. Compared with survivors, nonsurvivors had a higher incidence of preoperative cardiogenic shock, higher incidence of chronic kidney disease and end-organ failure, and longer aortic crossclamp times during surgery.

Conclusions: Early and midterm outcomes of modified infarct exclusion using the triple patch technique are acceptable. This technique is safe and simple, and may be useful for reducing postoperative residual shunt. ( $\mathrm{J}$ Thorac Cardiovasc Surg 2016;151:1711-6)

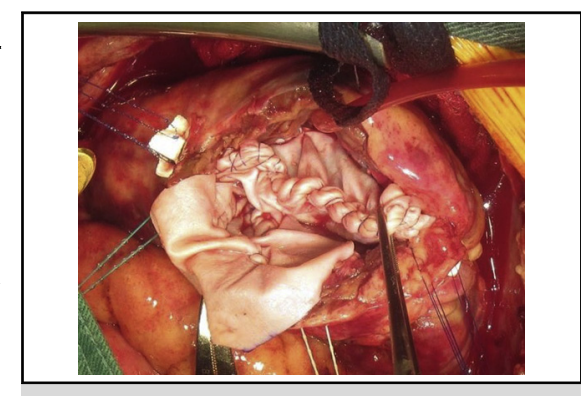

Triple patch technique

Central Message

A modified infarct exclusion using the triple patch technique is safe and useful for reducing postoperative residual shunt.

\section{Perspective}

Surgical repair for postinfarction ventricular septal defect is still a challenging procedure. We present a safe and simple modified infarct exclusion using the triple patch technique The technique was found to be reproducible with good late outcomes and to be useful for reducing postoperative residual shunt.

See Editorial Commentary page 1716.
Postinfarction ventricular septal defect (VSD) remains an important and life-threatening complication of myocardial infarction (MI). The prevalence is approximately $0.2 \%$ to $2 \%$ among patients with MI. ${ }^{1,2}$ Despite the development of numerous improvements in surgical techniques and materials, the mortality remains high. In addition, it is well known that residual shunt may affect cardiac function or late outcomes after VSD repair. ${ }^{2,3}$

In 2004, we began treating postinfarction VSD using the triple patch technique, which is a modified infarct exclusion method. We reported the surgical outcomes of 4 patients

\footnotetext{
From the Department of Cardiovascular Surgery, Tachikawa Medical Center, Nagaoka City, Niigata, Japan.

Received for publication Nov 18, 2015; revisions received Jan 13, 2016; accepted for publication Jan 20, 2016; available ahead of print April 1, 2016.

Address for reprints: Yuki Okamoto, MD, Department of Cardiovascular Surgery, Tachikawa Medical Center, 3-2-11 Kanda-cho, Nagaoka City, Niigata, Japan 940-0052 (E-mail: yamanashimedical@yahoo.co.jp). $0022-5223 / \$ 36.00$

Copyright (C) 2016 by The American Association for Thoracic Surgery http://dx.doi.org/10.1016/j.jtcvs.2016.01.056
}

using this new technique in 2008. ${ }^{1}$ This technique is simple and easy to perform, and is designed to minimize residual shunt, exclude infarcted myocardium, and regulate left ventricular volume. Herein, we review our experience in $21 \mathrm{pa}-$ tients who had postinfarction VSD and underwent VSD repair using the triple patch technique.

\section{MATERIALS AND METHODS \\ Patients}

Between April 2004 and September 2015, 21 consecutive patients presenting postinfarction VSD underwent VSD repair at Tachikawa Medical Center, Nagaoka City, Niigata, Japan. Clinical, echocardiographic, operative, and outcome data were collected prospectively. The study was approved by the institutional review board.

Scanning this QR code will take you to a procedural video. 


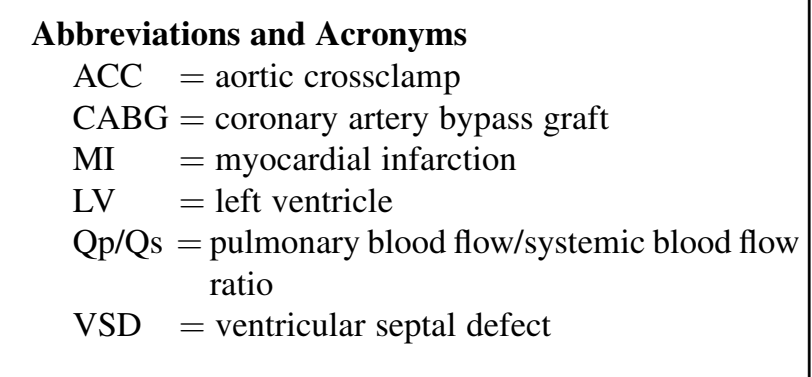

The patient demographic and clinical characteristics are summarized in Table 1. Preoperative echocardiography and coronary angiography were performed in all patients. The patients had a mean age of $73.2 \pm 9.5$ years (range, 49-88 years). Eight patients $(38.1 \%$ ) were in cardiogenic shock at the time of operation. An intra-aortic balloon pump was used in all patients preoperatively. In addition, preoperative percutaneous cardiopulmonary support was required in 2 patients $(9.5 \%)$. The mean and median times from MI to operation were $9.9 \pm 11.1$ and 7 days, respectively. Moreover, the mean and median times from VSD diagnosis to operation was $4.2 \pm 7.4$ and 2 days, respectively.

The preoperative mean left ventricular ejection fraction was $45.3 \% \pm 15.1 \%$. Eleven patients $(52.4 \%)$ had a left ventricular ejection fraction $\leq 40 \%$. The mean pulmonary blood flow to systemic blood flow ratio $(\mathrm{Qp} / \mathrm{Qs})$ was $2.86 \pm 0.91$ (range, 1.75-5.27).

\section{Surgical Technique}

Cardiopulmonary bypass was initiated using ascending aorta cannulation and bicaval cannulation under mild hypothermia. Myocardial revascularization, if necessary, was performed on the beating heart before repair of the VSD. Myocardial protection was achieved with antegrade cold blood cardioplegia, and the arrested state was maintained with intermittent retrograde cold blood cardioplegia. Operative schema is shown in Figure 1. Repair was done through a longitudinal left ventriculotomy in the infarcted area, about 1 to $2 \mathrm{~cm}$ away from the left anterior descending coronary artery (anterior type) or about 0.5 to $1 \mathrm{~cm}$ away from the posterior descending artery (posterior type). First, a tailored bovine pericardial patch was used to close the VSD directly with a running 4-0 polypropylene suture (Figure 2, A). Then, 2 bovine pericardial patches were cut into rectangular shapes (about $10 \mathrm{~cm} \times 10 \mathrm{~cm}$ ). One pericardial patch was sutured to the noninfarcted endocardium around the ventricular septal side, and the other patch was sutured to the noninfarcted endocardium on the anterolateral ventricular wall. In case of posterior type, 1 pericardial patch was sutured and fixed the fibrous annulus of the mitral valve, and the other patch was sutured to the posterior wall along a line of the medial margin of the base of the posteromedial papillary muscle.

Both patches were sutured with running 4-0 polypropylene sutures (Figure 2, B). These 2 patches were then cut and sewn to determine the ideal size and shape of the pouch fitting the left ventricular cavity. By means of this technique, left ventricle (LV) dimension is easily adjusted to avoid undersizing because we are able to directly look into the LV cavity and suture both patches. Then, fibrin glue, Bolheal (Chemo-Sero-Therapeutic Research Institute, Kumamoto, Japan) or Beriplast P Combi-Set (CLS Behring $\mathrm{GmbH}$, Marburg, Germany) was applied to fill the cavity between the first patch and the pouch. The ventriculotomy was closed in 2 layers with 2 polytetrafluoroethylene felt strips and 2-0 polypropylene sutures. Upon completion of the procedure, a terminal retrograde hot-shot cardioplegia was given and the crossclamp was released.

\section{Data Collection and Statistical Analysis}

Each patient's status and data after hospital discharge were determined from hospital visits and consultation with the family physician. The follow-
TABLE 1. Patient demographic characteristics $(\mathbf{N}=21)$

\begin{tabular}{|c|c|}
\hline Variable & Triple patch \\
\hline Age, $y$ & $73.2 \pm 9.5$ \\
\hline Range & $49-88$ \\
\hline$>75 y$ & 10 \\
\hline Gender, male/female & $13 / 8$ \\
\hline Body surface area, $\mathrm{m}^{2}$ & $1.51 \pm 0.20$ \\
\hline Hypertension & 11 \\
\hline Diabetes mellitus & 5 \\
\hline Hyperlipidemia & 2 \\
\hline Atrial fibrillation & 1 \\
\hline Stage 4 or $5 \mathrm{CKD}$ & 5 \\
\hline COPD & 1 \\
\hline Smoking & 8 \\
\hline \multicolumn{2}{|l|}{ Laboratory data } \\
\hline AST, IU/L & $283 \pm 378$ \\
\hline ALT, IU/L & $181 \pm 310$ \\
\hline Serum creatinine, $\mathrm{mg} / \mathrm{dL}$ & $1.45 \pm 0.92$ \\
\hline Shock status & 8 \\
\hline Preoperative IABP & 21 \\
\hline Preoperative PCPS & 2 \\
\hline Preoperative PCI & 1 \\
\hline Urgent or emergent status & 16 \\
\hline Duration from MI to operation, $\mathrm{d}$ & $9.9 \pm 11.1$ \\
\hline Duration from VSD diagnosis to operation, $\mathrm{d}$ & $4.2 \pm 7.4$ \\
\hline Median, d & 2 \\
\hline Ejection fraction, $\%$ & $45.3 \pm 15.1$ \\
\hline$<40 \%$ & 11 \\
\hline LVEDD, mm & $48.5 \pm 5.3$ \\
\hline LVEDS, mm & $35.7 \pm 5.4$ \\
\hline Qp/Qs & $2.86 \pm 0.91$ \\
\hline
\end{tabular}

$C K D$, Chronic kidney disease; $C O P D$, chronic obstructive pulmonary disease; $A S T$, aspartate aminotransferase; $A L T$, alanine transaminase; $I A B P$, intra-aortic balloon pump; $P C P S$, percutaneous cardiopulmonary support; $P C I$, percutaneous coronary intervention; $M I$, myocardial infarction; VSD, ventricular septal defect; $L V E D D$, left ventricular diastolic dimension; LVEDS, left ventricular systolic dimension; $Q p / Q s$, pulmonary/systemic blood flow ratio.

up data were $100 \%$ complete. The mean follow-up period for all patients was 43.5 months (range, 1-113 months). Echocardiographic examination were collected and evaluated in all patients at the preoperative, early postoperative and late operative stage.

Data are presented as mean \pm standard deviation. The Kaplan-Meier method was used to calculate the overall survival curve. The $\chi^{2}$ test (Fisher exact test when appropriate) or $t$ test was used to analyze categorical and continuous variables, respectively, between survivors and nonsurvivors. All statistical analyses were performed using the JMP 12.0 software package (SAS Institute Inc, Cary, NC).

\section{RESULTS}

Five patients underwent elective VSD repair $>7$ days after the onset of MI because of hemodynamic stability before surgery. The remainder underwent urgent or emergent surgery.

Operative data are shown in Table 2. The mean cardiopulmonary bypass and aortic crossclamp (ACC) time were $143 \pm 49$ minutes (range, 87-251 minutes) and $84 \pm 25$ minutes (range, 58-149 minutes), respectively. 


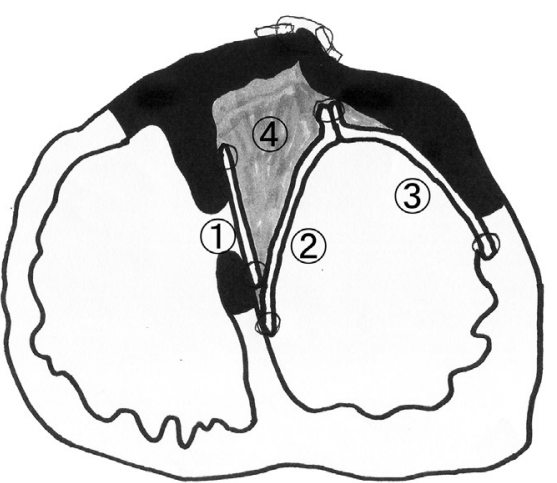

A

(1) first patch (2) second patch

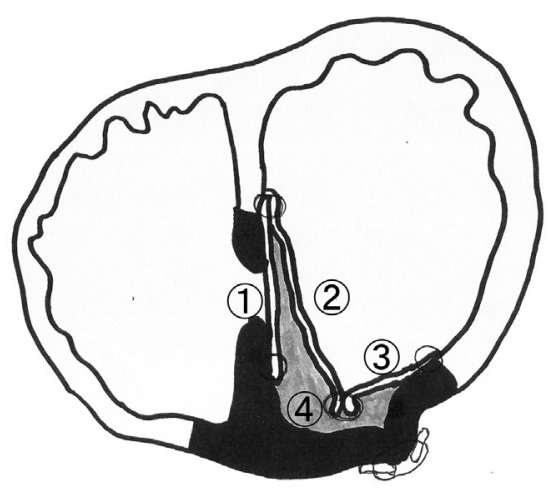

B

FIGURE 1. Operative schema. A, Anterior type. B, Posterior type. $1=$ First patch. 2 = Second patch. 3 = Third patch. $4=$ Fibrin glue.

An anterior VSD was repaired in 18 patients $(85.7 \%)$, and posterior VSD was repaired in 3 patients $(14.3 \%)$. Concomitant coronary artery bypass graft $(\mathrm{CABG})$ was performed in 8 patients $(38.1 \%)$.

The early and late outcomes of surgery are shown in Table 3. There were 5 deaths $(23.8 \%)$ within the first 30 days after surgery. All 5 of these patients were in cardiogenic shock preoperatively, and 1 of them had a posterior VSD. Three patients died due to low output syndrome and 2 patients died due to sepsis. There was no significant difference between preoperative left ventricular endodiastolic diameter and postoperative left ventricular endodiastolic diameter. Three patients $(14.3 \%)$ showed residual shunt after VSD repair (Qp/Qs $=1.7,1.6$, and 1.5, respectively). The residual shunt disappeared 6 months after VSD repair in 1 patient $(\mathrm{Qp} / \mathrm{Qs}=1.6 \rightarrow 1.0)$, has been decreasing gradually during follow-up in 1 patient $(\mathrm{Qp} / \mathrm{Qs}=1.7 \rightarrow 1.3)$, and remains unchanged in 1 patient $(\mathrm{Qp} / \mathrm{Qs}=1.5)$. During follow-up, angina pectoris requiring percutaneous coronary intervention occurred in 1 patient. There were 3 late deaths, and none of these were cardiac-related.

The overall survival is shown in Figure 3. The overall survival rates at 3 and 8 years were $70.8 \%$ and $57.9 \%$, respectively.

A comparison of pre- and perioperative variables between patients who survived and those who died during the first 30 days is shown in Table 4. Nonsurvivors were older than survivors, but the difference was not significant. There were significant differences in the presence of chronic kidney disease, preoperative cardiogenic shock, end-organ dysfunction, and ACC time between survivors and nonsurvivors.

\section{DISCUSSION}

It was reported that 30-day mortality rates and residual shunt rates range from $34.5 \%$ to $40.7 \%$ and from $22.8 \%$
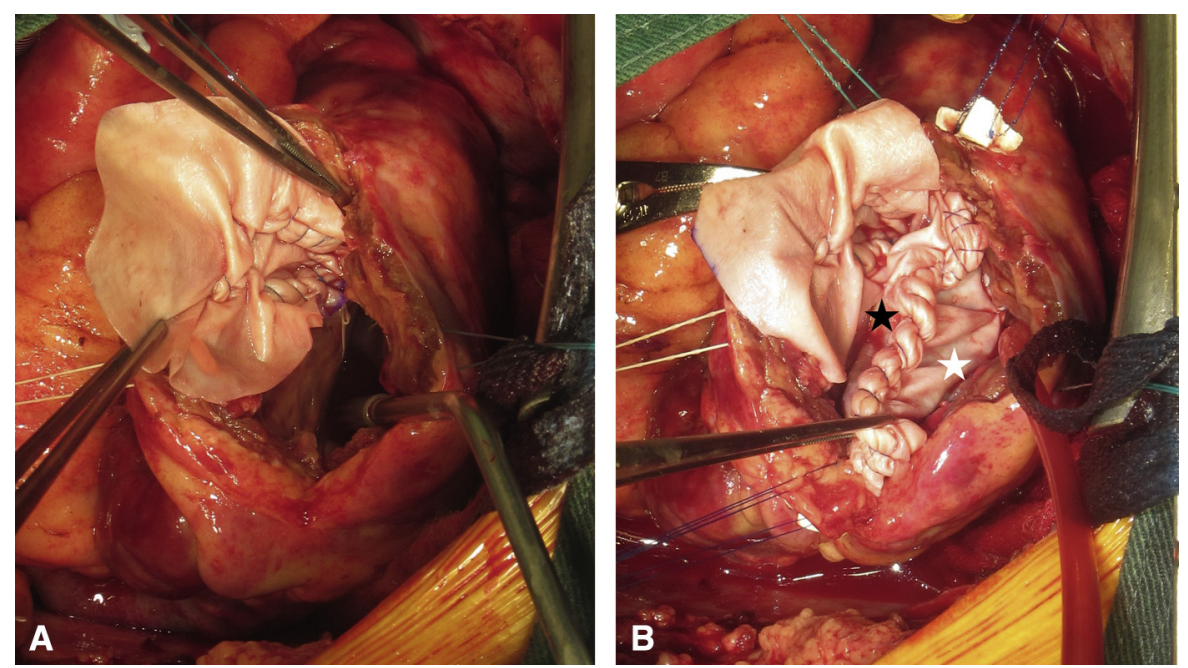

FIGURE 2. A, Ventricular septal defect closure by the first patch. B, A pouch made for the second (black star) and third patch (white star). Fibrin glue was applied to fill the cavity between the first patch and the pouch. 
TABLE 2. Operative data $(\mathbf{N}=21)$

\begin{tabular}{lc}
\hline \multicolumn{1}{c}{ Variable } & Triple patch \\
\hline Cardiopulmonary bypass time, min & $143 \pm 49$ \\
Aortic crossclamp time, min & $84 \pm 25$ \\
Ventricular septal defect & \\
Anterior & 18 \\
Posterior & 3 \\
Concomitant CABG & 8 \\
$\quad$ Distal anastomosis & $1.25 \pm 0.46$ \\
\hline$C A B G$ Coronary artery bypass graft.
\end{tabular}

to $37.6 \%$, respectively, after VSD repair of postinfarction VSD. $^{2-5}$ In our study, 30 -day mortality was $23.8 \%$ and residual shunt rate was $14.3 \%$. Therefore, our study showed that modified infarct exclusion triple patch technique was not inferior to David infarct exclusion repair or Daggett direct septal closure technique.

Some authors reported that hemodynamic conditions, in particular cardiogenic shock, significantly influence mortality after VSD repair. ${ }^{6}$ Furthermore, they also concluded that the time from acute MI to operation appears to be an important prognostic factor. ${ }^{6}$ Indeed, in our study, 5 early deaths were in patients who had preoperative cardiogenic shock. In addition, similar to their outcomes, our study demonstrated that the mean time from MI to VSD repair in nonsurvivors tended to be shorter than the time in survivors $(5.6 \pm 4.2 \mathrm{vs}$

TABLE 3. Early and late outcomes $(N=21)$

\begin{tabular}{lc}
\hline \multicolumn{1}{c}{ Variable } & Triple patch \\
\hline Early outcome & \\
Complications & \\
$\quad$ LOS & 3 \\
Stroke & 3 \\
$\quad$ Sepsis & 2 \\
Death & \\
30 d & 5 \\
In hospital & 5 \\
Ejection fraction, \% & $43.5 \pm 9.6$ \\
LVEDD, mm & $46.7 \pm 6.4$ \\
LVEDS, mm & $35.1 \pm 5.6$ \\
Residual shunt & 3 \\
Qp/Qs & $1.07 \pm 0.18$ \\
$\quad$ Range & $0.9-1.7$ \\
NYHA functional class & $1.1 \pm 0.3$ \\
Late outcome & \\
Angina pectoris & 1 \\
Reoperation & 0 \\
Residual shunt & 2 \\
Op/Qs & $1.03 \pm 0.08$ \\
Death & 3 \\
Cardiac related & 0 \\
Other causes & 3 \\
NYHA functional class & $1.2 \pm 0.4$ \\
\hline LOS, Low output syndrome; LVEDD, left ventricular endodiastolic dimension; \\
LVEDS, left ventricular endosystolic dimension; $Q p / Q s$, pulmonary/systemic blood \\
flow ratio; NYHA, New York Heart Association. \\
\end{tabular}

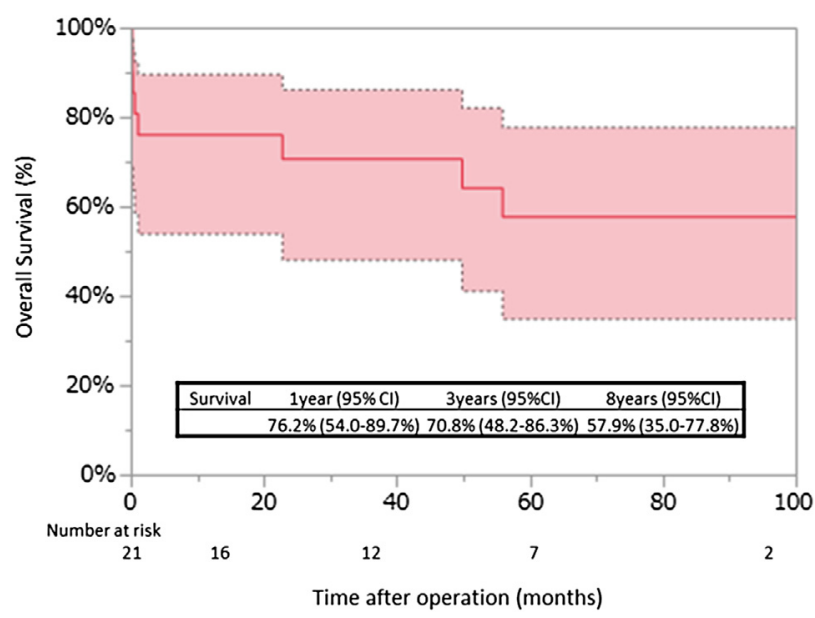

FIGURE 3. Kaplan-Meier overall survival at $95 \%$ confidence interval estimate for patients who underwent ventricular septal defect repair. $C I$, Confidence interval.

$11.3 \pm 12.3$ days, respectively). Our findings suggest that it may be desirable to delay VSD repair following MI if a patient's condition is hemodynamically stable.

Mantovani and colleagues ${ }^{7}$ reported that among the mortality predictors was an ACC time $>100$ minutes. In our study, the mean ACC time in nonsurvivors was significantly longer than that in survivors ( $103 \pm 36$ vs $78 \pm 17$ minutes, respectively). Although we believe that it is important to shorten the ACC time as much as possible during surgery, the worse outcome in cases with longer ACC may be related to differences in the original disease rather than the actual duration of myocardial ischemia. Coronary revascularization for postinfarction VSD has been controversial. Some authors reported that early or midterm mortality was not influenced by concomitant $\mathrm{CABG}^{2,7}$ On the other hand, others reported that no or incomplete revascularization was an independent predictor of mortality, and that complete revascularization improved long-term survival. ${ }^{8,9}$

Perrotta and colleagues ${ }^{10}$ suggested that concomitant CABG of all stenotic coronary arteries supplying noninfarcted myocardium results in less early mortality and better long-term survival, and that improvement of collateral flow to the myocardium contributes to better recovery. In our study, most of the culprit arteries were totally occluded. Revascularization of the culprit artery was performed in only 2 patients. One of them underwent percutaneous coronary intervention before VSD repair. Seven patients underwent $\mathrm{CABG}$ for stenotic coronary arteries, but not the culprit artery. We also believe that total revascularization of stenotic coronary arteries, but not the culprit artery, may improve early mortality and long-term survival. Of course, to shorten ACC time, it is preferable to perform CABG on a beating heart.

We performed VSD repair by the David-Komeda infarct exclusion method ${ }^{11,12}$ between 1996 and 2003. However, 
TABLE 4. A comparison between patients who survived or died during the first 30 days $(\mathbf{N}=\mathbf{2 1})$

\begin{tabular}{|c|c|c|c|}
\hline Variables & Alive $(n=16)$ & $\operatorname{Dead}(n=5)$ & $P$ value \\
\hline Age, y & $71.8 \pm 9.6$ & $79.8 \pm 5.6$ & .075 \\
\hline Range & $49-88$ & $74-87$ & - \\
\hline$>75$ & 6 & 4 & .149 \\
\hline Female sex & 8 & 5 & .111 \\
\hline Body surface area, $\mathrm{m}^{2}$ & $1.48 \pm 0.22$ & $1.58 \pm 0.12$ & .369 \\
\hline Hypertension & 8 & 3 & 1.000 \\
\hline Diabetes mellitus & 5 & 0 & .278 \\
\hline Hyperlipidemia & 1 & 1 & .429 \\
\hline Atrial fibrillation & 0 & 1 & .238 \\
\hline Stage 4 or $5 \mathrm{CKD}$ & 1 & 4 & .004 \\
\hline COPD & 0 & 1 & .238 \\
\hline Smoking & 7 & 1 & .607 \\
\hline \multicolumn{4}{|l|}{ Laboratory data } \\
\hline AST, IU/L & $189 \pm 251$ & $583 \pm 575$ & .039 \\
\hline ALT, IU/L & $104 \pm 157$ & $428 \pm 538$ & .038 \\
\hline Serum creatinine, $\mathrm{mg} / \mathrm{dL}$ & $1.2 \pm 0.83$ & $2.25 \pm 0.74$ & .022 \\
\hline Shock status & 3 & 5 & .003 \\
\hline Preoperative IABP & 14 & 5 & 1.000 \\
\hline Preoperative PCPS & 1 & 1 & .429 \\
\hline Preoperative PCI & 0 & 1 & .238 \\
\hline Urgent or emergent status & 11 & 5 & .278 \\
\hline $\begin{array}{l}\text { Duration from MI to } \\
\text { operation, } \mathrm{d}\end{array}$ & $11.3 \pm 12.3$ & $5.6 \pm 4.2$ & .332 \\
\hline $\begin{array}{l}\text { Duration from VSD diagnosis } \\
\text { to operation, } \mathrm{d}\end{array}$ & $5.3 \pm 8.2$ & $0.8 \pm 0.8$ & .250 \\
\hline Median, d & 4 & 1 & - \\
\hline Ejection fraction, $\%$ & $45.7 \pm 16.9$ & $44.0 \pm 8.2$ & .831 \\
\hline$<40 \%$ & 8 & 3 & 1.000 \\
\hline LVEDD, mm & $49.8 \pm 4.4$ & $46.8 \pm 6.4$ & .373 \\
\hline LVEDS, mm & $36.3 \pm 5.1$ & $35.0 \pm 6.3$ & .706 \\
\hline $\mathrm{Qp} / \mathrm{Qs}$ & $2.73 \pm 0.73$ & $3.90 \pm 1.94$ & .087 \\
\hline $\begin{array}{l}\text { Cardiopulmonary bypass } \\
\text { time, } \min \end{array}$ & $130 \pm 38$ & $184 \pm 62$ & .104 \\
\hline Aortic crossclamp time, min & $78 \pm 17$ & $103 \pm 36$ & .002 \\
\hline \multicolumn{4}{|l|}{ Ventricular septal defect } \\
\hline Anterior & 14 & 4 & 1.000 \\
\hline Posterior & 2 & 1 & 1.000 \\
\hline Concomitant $\mathrm{CABG}$ & 5 & 3 & .653 \\
\hline Distal anastomosis & $1.40 \pm 0.55$ & 1.00 & - \\
\hline Residual shunt & 3 & 0 & .549 \\
\hline
\end{tabular}

$C K D$, Chronic kidney disease; $C O P D$, chronic obstructive pulmonary disease; $A S T$, aspartate aminotransferase; $A L T$, alanine transaminase; $I A B P$, intra-aortic balloon pump; $P C P S$, percutaneous cardiopulmonary support; $P C I$, percutaneous coronary intervention; $M I$, myocardial infarction; VSD, ventricular septal defect; $L V E D D$, left ventricular diastolic dimension; $L V E D S$, left ventricular systolic dimension; $Q p / Q s$, pulmonary/systemic blood flow ratio; $C A B G$, coronary artery bypass graft.

residual shunt was present after surgery in $50 \%$ of cases (mean postoperative $\mathrm{Qp} / \mathrm{Qs}=1.87$; range, 1.5-2.7). One patient underwent a second operation for VSD recurrence. We speculated that this problem might depend on the technical complexity of the procedure. Therefore, we modified the conventional infarct exclusion technique to easily determine the size and shape of the left ventricular pouch, and to make it simple to suture the patch to the myocardium and adequately regulate left ventricular volume because we directly look into the LV cavity and are able to suture the second and the third patches.

There were 3 patients in our study with small residual shunt. In these 3 patients with residual shunt after VSD repair, residual shunt flow disappeared 6 months after surgery in 1 patient, and has been decreasing gradually in another during follow-up. Importantly, the residual shunt flow did not worsen over time, and in most cases improved.

It has been suggested that surgical repair of posterior VSD carries higher rates of mortality and morbidity than does repair of anterior VSD. ${ }^{1,2}$ However, VSD repair using the triple patch technique is easily performed for both anterior and posterior VSDs, and there was no residual shunt in patients with posterior VSD in our limited experience.

Several limitations of the present study should be noted. All the data were prospectively collected, but this was a retrospective and nonrandomized study; therefore, there may be selection bias. Furthermore, the number of study patients was relatively small.

\section{CONCLUSIONS}

Early and midterm outcomes of modified infarct exclusion using the triple patch technique are acceptable. This technique is safe and simple, and may be useful for reducing postoperative residual shunt.

\section{Conflict of Interest Statement}

Authors have nothing to disclose with regard to commercial support.

\section{References}

1. Sugimoto T, Yoshii S, Yamamoto K, Sakakibara K, Iida Y, Uehara A, et al. A modified infarct exclusion technique: triple-patch technique for postinfarction ventricular septal perforation. J Thorac Cardiovasc Surg. 2008; 135:702-3.

2. Jeppsson A, Liden H, Johnsson P, Hartford M, Rådegran K. Surgical repair of post infarction ventricular septal defects: a national experience. Eur J Cardiothorac Surg. 2005;27:216-21.

3. Fukushima S, Tesar PJ, Jalali H, Clarke AJ, Sharma H, Choudhary J, et al. Determinants of in-hospital and long-term surgical outcomes after repair of postinfarction ventricular septal rupture. J Thorac Cardiovasc Surg. 2010;140: 59-65.

4. Deja MA, Szostek J, Widenka K, Szafron B, Spyt TJ, Hickey MS, et al. Post infarction ventricular septal defect-can we do better? Eur J Cardiothorac Surg. 2000;18:194-201.

5. Lundblad R, Abdelnoor M. Surgery of postinfarction ventricular septal rupture: the effect of David infarct exclusion versus Daggett direct septal closure on early and late outcomes. J Thorac Cardiovasc Surg. 2014;148:2736-42.

6. Papalexopoulou N, Young CP, Attia RQ. What is the best timing of surgery in patients with post-infarct ventricular septal rupture? Interact Cardiovasc Thorac Surg. 2013;16:193-6.

7. Mantovani V, Mariscalco G, Leva C, Blanzola C, Sala A. Surgical repair of postinfarction ventricular septal defect: 19 years of experience. Int J Cardiol. 2006; 108:202-6.

8. Barker TA, Ramnarine IR, Woo EB, Grayson AD, Au J, Fabri BM, et al. Repair of post-infarct ventricular septal defect with or without coronary artery bypass 
grafting in the northwest of England: a 5-year multi-institutional experience. Eur J Cardiothorac Surg. 2003;24:940-6.

9. Lundblad R, Abdelnoor M, Geiran OR, Svennevig JL. Surgical repair of postinfarction ventricular septal rupture: risk factors of early and late death. $J$ Thorac Cardiovasc Surg. 2009; 137:862-8

10. Perrotta S, Lentini S. In patients undergoing surgical repair of post-infarction ventricular septal defect, does concomitant revascularization improve prognosis? Interact Cardiovasc Thorac Surg. 2009;9:879-87.
11. David TE, Dale L, Sun Z. Postinfarction ventricular septal rupture: repair by endocardial patch with infarct exclusion. J Thorac Cardiovasc Surg. 1995;110:1315-22.

12. Komeda M, Fremes SE, David TE. Surgical repair of postinfarction ventricular septal defect. Circulation. 1990;82(5 Suppl):IV243-7.

Key Words: myocardial infarction, coronary artery bypass grafting, ventricular septal defect, cardiac surgery

\title{
EDITORIAL COMMENTARY
}

\section{Postinfarction ventricular septal defect: Beyond patching the hole}

\author{
Juan A. Crestanello, MD
}

From the Division of Cardiac Surgery, Wexner Medical Center, The Ohio State University, Columbus, Ohio.

Disclosures: Author has nothing to disclose with regard to commercial support.

Received for publication Feb 7, 2016; accepted for publication Feb 10, 2016; available ahead of print March 8, 2016.

Address for reprints: Juan A. Crestanello, MD, Division of Cardiac Surgery, Wexner Medical Center, N-820 Doan

Hall 410 West 10th Ave, Columbus, OH 43210 (E-mail: juan.crestanello@osumc.edu).

J Thorac Cardiovasc Surg 2016;151:1716-7

$0022-5223 / \$ 36.00$

Copyright (C) 2016 by The American Association for Thoracic Surgery

http://dx.doi.org/10.1016/j.jtcvs.2016.02.024

Postinfarction ventricular septal defect (VSD) remains a formidable surgical challenge with high operative mortality, high rate of residual-recurrent shunt, and decreased long-term survival. ${ }^{1,2}$ Three main issues remain controversial in the care of these patients: (1) timing of the surgery, (2) surgical technique, and (3) how to mange the tremendous preoperative and postoperative physiologic derangements that these patients have. In addition, these cases are rare, and no single surgeon has a large experience treating these patients.

In terms of timing of surgery, most authors agree that early surgery is beneficial because medical management alone is almost uniformly fatal. ${ }^{3,4}$ However, early surgery was associated with substantially increased operative mortality in a recent report of the Society of Thoracic Surgeons database that included more than 2800 patients with postinfarction VSD. ${ }^{1}$ This is likely explained by selection bias when patients with more severe hemodynamic compromise underwent operation earlier. On the other hand, delaying surgery hoping to "stabilize" the patient and for the "edges of the VSD to mature" works only in very selected patients with less hemodynamic compromise and potentially exposes them to congestive heart failure and cardiogenic shock for longer periods of time, increasing the incidence of end-organ dysfunction. The patients who were considered too sick to undergo surgery or those who died awaiting surgery were not reported in that article. ${ }^{1}$

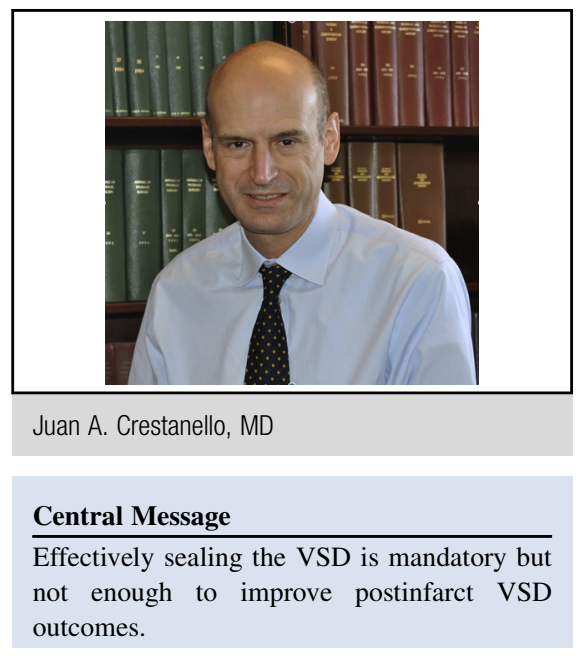

See Article page 1711

The conventional management of the hemodynamic and physiologic derangements (heart failure, cardiogenic shock) associated with an acute VSD is demanding and not always successful. ${ }^{4}$ The widespread availability of venoarterial extracorporeal membrane oxygenation and other temporary circulatory support devices allows for perioperative support of these patients and potentially for patient optimization and surgery at a delayed stage, and may result in improved survival.,

The technical aspects associated with VSD repair have remained challenging. From the early description of Cooley and colleagues ${ }^{7}$ to the most recent report in this issue of the Journal, ${ }^{8}$ many techniques have been described to address the frailty of the tissues and prevent recurrent or residual VSD. ${ }^{9,10}$ The high rate of recurrent-residual VSD is related not only to the surgical technique but also to the extension and location of the myocardial infarction and therefore 